\title{
WAR SURGERY IN THE KOREAN CAMPAIGN
}

\author{
By Lт.-Col. J. C. WatTs, M.C., F.R.C.S., R.A.M.C. \\ Adviser in Surgery, British Troops in Austria
}

The Korean campaign fell roughly into five phases, namely the retreat before superior forces following the aggression by North Korea, the rapid advance and rout of the North Korean Army when the United Nations' forces almost reached the Manchurian border, the Chinese intervention and subsequent rapid withdrawal, followed by the series of counter attacks which regained the territory of South Korea and, finally, the fighting on relatively static lines until the armistice.

Two special factors influenced the medical arrangements of the campaign; these were the climate of Korea and the possession of air supremacy by the United Nations' forces.

The British Commonwealth contribution to the United Nations' forces consisted originally of the Ist Battalion of the Australian Regiment, which had been garrisoning Japan. This was soon joined by two battalions from Hong Kong and a Brigade Headquarters to form the $27^{\text {th }}$ Brigade. In November 1950 the 29th Brigade Group and a General Hospital came out from England, one battalion of Canadian troops and a Field Regiment of the Royal New Zealand Artillery arrived and India sent a Parachute Field Ambulance. Finally, the arrival of two more Canadian battalions and a Brigade Headquarters and other troops, including a Canadian Field Ambulance and Field Dressing Station, completed the Canadian Brigade and a Commonwealth Division was formed.

Unfortunately there was no Casualty Clearing Station, so although a British Forward Surgical Team was available, for lack of a suitable parent unit the evacuation of Commonwealth troops from the Division was via a Mobile Surgical Army Hospital or M.A.S.H., an American unit roughly corresponding to our C.C.S. in function, then to the General Hospital in Japan, which in addition to receiving all Commonwealth casualties also took a number of French, Dutch and Turkish patients. The Commonwealth General Hospital consisted of an integration of the original Australian General Hospital of 200 beds, a British General Hospital of 400 beds, later increased to 600 , and a roo-bed Canadian contingent. This integration, though leading to certain administrative difficulties, $\vec{\omega}$ worked extremely harmoniously and patients were $\frac{\text { s }}{\circ}$ not segregated nor were wards staffed exclusively by nationals of any one country.

The types of casualty met with were mostly bullet wounds and hand grenade injuries in the early phases, later the shell and mine wound formed the majority; frost-bite formed a very $N$ real hazard in the first winter, but was not so 음 marked in the winter of $1951 / 52$ when better equipment was available and when better training $c$ in the prevention of cold injury had been exercised.

Before discussing the management of casualties, the present position in war surgery will be briefly outlined.

Battle casualties not killed instantly die fron one of six main causes:

I. Haemorrhage.

2. Interference with respiration.

3. Hypotension (sustained), viz., neurogenic shock, hypotensive shock and Crush syndrome.

4. Embolism, fat, blood clot, air or foreign body.

5. Infection

6. Starvation.

The only valid 'principles of war surgery' are saving life and restoring function; all the socalled principles are methods and liable to modification according to the circumstances of the campaign, and often the ideal methods of preventing the above fatal complications are impracticable or impossible.

The main factors modifying the theoretically ideal treatment of wounds can be grouped together under the transatlantic neoligism of 'logistics,' that is to say, considerations of time, space, supply and movement; battle casualties occur in numbers out of all proportion to civil catastrophies; the surgical centres at which they are treated are improvised and mobile and the casualties must be evacuated from the field, often for many miles.

For convenience the treatment of the wounded may be considered under four phases: First aid, forward surgery, reparative surgery and re- 
constructive surgery. These stages normally occur at the Regimental Aid Post, the Advanced Surgical Centre, the General Hospital at the base and at selected centres in the United Kingdom, respectively.

\section{First Aid}

This should be expeditiously carried out so that the case may be evacuated without delay to the Advanced Surgical Centre, and is concerned mainly with the control of haemorrhage, preferably by direct pressure or the application of artery forceps; tourniquets are dangerous and seldom necessary, but if used should be placed as low as possible as amputation at the level of the tourniquet may be required if the evacuation of the case is delayed. The commonest error in tourniquet application is to have it too loose so that haemorrhage is increased by venous engorgement (it is by no means uncommon to find that haemorrhage in the presence of a tourniquet ceases on removal). In addition, establishment and maintenance of unembarrassed respiration in cases of chest wounds, neck wounds, facial and jaw wounds and in patients unconscious from any cause is vital. These patients must be evacuated in the ' coma' position, that is to say on the side, with the knees and thighs flexed, the upper limb more than the lower, the lower arm behind the patient with a pillow supporting the chest; on no account should any patient liable to respiratory embarrassment be evacuated supine, and unconscious patients should be turned from left to right coma position and vice rersa at hourly intervals.

In addition to the above, the control of sucking chest wounds and tracheotomy in indicated cases must be done at R.A.P. level. Antibiotic therapy can, with advantage, be initiated at this level, but unless evacuation is not possible intravenous resuscitative measures are best left until the patient's arrival at the Advanced Surgical Centre as they serve only to delay evacuation; the patient's condition deteriorates again during transport and it was common experience that a second attempt to resuscitate a shocked patient was seldom successful. Control of pain and shock by adequate splintage of the injured part and by the administration of morphia if it is really required should be performed, but all narcotics should be avoided in cases of head injury in favour of physical restraint. Finally, adequate notes on the time and type of wound and the physical state of the patient, especially on the level of consciousness, which should be expressed factually as 'Knows name and number but not date or place' rather than by statements such as 'semi-conscious,' should be made on the field medical card with notes on treatment and drugs administered.

\section{Advanced Surgical Centre}

This should be sited as far forward as is possible, compatible with the avoidance of hostile activity (wounded men do badly if nursed under shell fire) and the desirability of being able to hold cases, if necessary, for up to ten days. It is often tactically necessary to divide the Advanced Surgical Centre with Field Surgical Units at a Field Dressing Station ahead of the Casualty Clearing Station which normally forms the hub of the Advanced Surgical Centre, but this plan necessitates careful selection of cases to decide which require priority, otherwise the small F.D.S., with its relatively inadequate nursing facilities, is rapidly overwhelmed. Ideally, cases should reach the Advanced Surgical Centre within six hours, and a delay of longer than 12 hours should not be tolerated.

The function of the Advanced Surgical Centre is to make permanent the control of haemorrhage and freedom from respiratory embarrassment established at the R.A.P., to prevent infection by the surgical excision of wounds and the relief of tension, to treat blood loss and shock by transfusion which is also the principal factor in preventing lower nephron nephrosis (the Crush syndrome). The patient is made transportable by adequate plaster of paris splintage not only in fractures but also in massive flesh wounds; these plasters must be padded and bivalved for transport.

Transfusion is required by most severely wounded cases at the Advanced Surgical Centre, and this transfusion should be massive and aim at restoring the circulating blood volume. Transfusions of six or seven pints are by no means uncommon and the average figure is about four pints. Failure to respond to transfusion may be due to one of the following complications: Internal haemorrhage, peritonitis, gas gangrene, tension pneumothorax, embolism or cerebral malaria. These must be rapidly detected and treated appropriately.

Eighty per cent. of wounds occur in the limbs, with or without fracture, and in these cases the main danger to life and to recovery of function is from infection. This is prevented by the adequate excision of all dead and contaminated tissue with longitudinal tension relieving incisions; as little skin as possible is removed but dead muscle is ruthlessly excised and foreign bodies, particularly clothing, are removed. A prolonged search for deeply embedded metallic foreign bodies is unnecessary. Haemostasis is secured; the wound lightly frosted with penicillin-sulphonamide powr der and an occlusive dressing (with plaster splinting if required) applied; these cases can be evacuated as soon as they are-round from the anaesthetic.

Head Wounds. These cases travel well, they 
are seldom subject to shock or severe haemorrhage, and their adequate surgical treatment requires both time and specialized experience. For these reasons they should be evacuated without loss of time to neurosurgical centres. They form about 2 per cent. of casualties and, if they cannot be evacuated, either for tactical reasons or because of their rapidly deteriorating condition, then a careful surgical excision of the wound, after a complete shaving of the head, and with the lifting of an osteoplastic flap if necessary must be performed. All disorganized brain must be removed by judicious use of the sucker, and all bone fragments detected and removed.

The dura should be closed, with fascial grafts if necessary, and the scalp incision carefully closed in layers. These cases must then be held for six to seven days as stitches and ambulance cars are incompatible.

Faciomaxillary Wounds (I per cent.). These cases should be treated in conjunction with the dental surgeon from the start. Establishment of a clear airway, control of haemorrhage and fixation of the jaw in normal occlusion must be achieved and then a primary suture of the facial wound is performed or a skin to mucosa stitch if the former is impracticable. These cases form an exception to the rule given above if they can travel sitting, and they can be evacuated early.

Chest Wounds (8 to ro per cent.). Closure of the pleura with aspiration of blood should be performed to prevent suction haemopneumothorax and cardiac tamponade and the case held until unembarrassed respiration is established.

Abdominal Wounds (2 to 4 per cent.). Whilst early surgery in abdominal wounds is life saving, these cases must be held post-operatively for about ten days until normal peristalsis is firmly established, also these cases progress unfavourably if exposed to shellfire or to improvized and often inexpert post-operative nursing conditions, so it is ibest to evacuate these cases to C.C.S. level rather than deal with them in an Advanced Surgical Centre established in a Divisional area. Preoperatively a transfusion should be set up and a nasal duodenal tube passed; the nerve function of the extremities should be tested as some abdominal wounds involve the spinal cord and laminectomy, if indicated, should be performed first. Unless it is certain that only a local area of the peritoneal cavity is involved (as in perforating gunshot wounds) a paramedian incision should be employed; mid-line incisions are quicker and may be used if the pressure of work is very great, but they are more liable to complications, such as ruptured abdomen and incisional hernia, under active service conditions.

Haemorrhage should be controlled first, the spleen, if bleeding, being removed, large tears in the liver being oversewn but small wounds of the liver can be left with impunity. The alimentary canal is then examined systematically and artery forceps placed on any perforation discovered; repair should not be started until all lesions have been located in case resection of a damaged segment is indicated, as it is better to do as few resections as possible, even if several feet of small intestine have to be sacrificed. Wherever possible intestinal perforations are sewn up longitudinally; my own preference is for interrupted Lembert sutures of catgut. Wounds of the large bowel should, if mobile, be exteriorized, but if in fixed parts of the bowel then a proximal colostomy should be performed; this colostomy should be performed through a separate muscle splitting incision. Colostomy should also be performed for all large buttock and perineal wounds.

Post-operatively, naso-duodenal suction and intravenous fluid replacement must be continued; in the field the urine forms the main measure of fluid balance and its output and chlorides (using Fantus test) must be measured.

\section{Reparative Surgery}

At general hospitals the bulk of surgery is the closure of wounds by delayed primary suture This procedure is still misunderstood and is bes regarded as the continuation of the first operation with an interval of five days during which the patient is evacuated and the oedema which is invariable in missile wounds subsides. The forward surgeon has excised the wound and secured haemostasis, and all that remains to be done is to close the wound. No excision should be necessary unless obviously, dead tissue is present, the skin edges are gently ' unstuck' from the underlying wound and closed with interrupted sutures without tension. If tension prevents complete closure then partial closure by suture is effected and split skin in the form of 'postage stamp' grafts is applied to the defect. A wound swab may be taken, but delayed primary suture is best carried out at the first inspection of the wound and is not 0 delayed until the wound swab result is to hand.

Gas Gangrene. It is at this stage in the wounded man's evacuation that gas gangrene is most likely to be met with, although it may be seen in the Advanced Surgical Centre, especially when evacuation is delayed. The diagnosis of gas gangrene is based on clinical grounds alone, as bacterial and radiological evidence of the disease is unreliable, since clostridia are found in many wounds and gas shadows are seen in anaerobic cellulitis but not in gas gangrene at the amenable stage.

Gas gangrene can only occur in ischaemic muscle, so if the excision of the wound has been 
adequately carried out then it should not occur. Whilst a dry form of gas gangrene occurs the wet form is that most commonly seen; the patient is usually ill and febrile with a rapid pulse, but the characteristic feature is the copious, sweetsmelling discharge, usually having a faint greenish tinge, appropriately described as 'green Chartreuse.' It is commonly found that the wound has had extra dressings applied to it en route, but in spite of this leakage of discharge on to the stretcher has occurred. The appearance of this clinical picture is a signal for immediate surgical interference and the wound must be opened up widely and all muscle which does not contract on pinching and bleed on cutting should be ruthlessly excised. Formal dissection of muscle groups is not called for if the disease is treated early, and amputation is only necessary if the muscle ischaemia is so widespread that excision would leave a non-functioning limb. The wound is left widely open after haemostasis has been secured and massive transfusion with heavy penicillin administration ( one mega unit three-hourly) continued until the patient's condition is satisfactory. A muscle section of the excised muscle will show the characteristic histological picture, a useful confirmation of the diagnosis as the radical nature of the excision in the absence of obviously diseased muscle may lead one's less experienced colleagues to regard one as a butcher rather than a surgeon. Skin grafting or delayed primary suture can be carried out, and the functional results, in spite of the vast loss of muscle, are usually most gratifying. One case in which almost all of gastrocnemius and part of soleus was excised was grafted after ten days and walking in one month.

The treatment of chest wounds at the base hospital is most important and is largely the treatment of haemothorax. The pleural cavity must be cleared of all blood by daily aspiration and radiological checking performed. Quite large haemothoraces may be symptomless and thus overlooked, the patient is discharged apparently well but the organization of the haemothorax and its subsequent fibrosis will in six to twelve months produce what has been picturesquely called the 'pulmonary cripple' with a contracted nonfunctioning.lung. If aspiration fails to clear the pleural cavity then decortication should be performed, preferably between the third and sixth week when the fibrin envelope of the visceral pleural can be most easily stripped off and the lung re-expanded under direct vision. Foreign bodies causing symptoms, or of any magnitude $(1 \mathrm{~cm}$. in their longest dimension has been arbitrarily selected as the criterion) are removed at thoracotomy after careful radiological location.

It is customary for a holding policy to be laid down by the medical directorate and cases who are likely to exceed the stipulated time limit are evacuated home as soon as they can travel in safety. Included in this category, of course, are those likely to be discharged as unfit. It is important for the morale of the patient that this decision is made as early as possible.

The remainder of the surgery at base hospitals is very comparable with that in civilian life and will not be further dicussed here, nor will that surgery coming under the heading of 'Reconstructive Surgery;' i.e., peripheral nerve repair, major orthopaedic work and extensive plastic procedures.

The above brief outline of the scope of war surgery is affected materially by the nature of the campaign and by the training, experience and amount of surgical staff available. At the beginning of the Korean campaign the vastly outnumbered American occupation forces were faced with a rapid and unprepared retreat, field medical units were scarce and most of the surgeons were completely lacking in field experience.

The saving feature was that with air supremacy and a very efficient air evacuation service most of the wounded were successfully evacuated to Japan, and although the common errors of inadequate excision and incision of wounds, primary suture and tight packing of wounds were occasionally met with and caused much increased morbidity, deaths due to inadequate care were extremely rare. It appeared that the North Korean forces expected a 'walk over' and as their attack lost its momentum, in face of a stiffening resistance, the United Nations' forces were enabled to mount a counter offensive which carried them almost to the borders of Manchuria, and the war appeared to be over.

Then came the Chinese intervention and again the long weary retreat took place, this time in winter conditions of a severity unparalleled in the history of our Army.

The treatment of cold injury has been the subject of a separate paper (R.A.M.C. Fournal, January 1952) and will not be discussed here except to mention that, contrary to expectations, the incidence of cold injury among the wounded was remarkably low (2.4 per 1,000$)$, a remarkable tribute to the efficiency of the collection of wounded in the field. A series of limited United Nations' counter attacks early in $195 \mathrm{I}$ resulted in the establishment of a line not differing greatly from the original partition line and, in spite of repeated attempts by the Chinese, notably at the Imjin River Battle in April 1951, these positions remained basically the same until the cessation of hostilities.

The forward surgery of the Commonwealth 
forces was carried out in the American M.A.S.H. and later in a Norwegian M.A.S.H., which supported the Commonwealth Division after its formation, but a British Field Surgical Team (the F.S.U. of the last war) was in Korea from October I950 to March I95I, attached to various American M.A.S.H.s, and later Commonwealth surgeons were attached for short periods to the Norwegian M.A.S.H.

The Commonwealth General Hospital at.Kure, in Japan, took all Commonwealth cases except neurosurgical ones, which were treated at the American neurosurgical centre in Tokyo. During the first year of the campaign admissions of battle casualties to the Commonwealth Hospital averaged I 66 per month, the busiest period being the Imjin River Battle, when 254 admissions occurred between April 26 and 30. During the same time there was a monthly average of 323 non-battle surgical admissions.

Operations averaged 360 per month, 162 on battle casualties (it will be noted that most battle casualties require more than one operation). Deaths averaged 3.53 per 1,000

All cases received prophylactic penicillin during evacuation and no penicillin sensitive organisms were grown from wound swabs taken at the base base hospital; the delayed primary suture was. successful in 99.6 per cent. of the cases in which it was employed.

Early skin grafting was the rule in all cases where D.P.S. was not practicable.

The grafting of massive buttock wounds presents difficulties in dressing the graft so that it does not become detached or soiled, and this led Lt.-Col. E. S. R. Hughes, R.A.A.M.C., who was the senior Australian surgeon at the time, to try the procedure of leaving the postage stamp grafts exposed to the air, without dressings and then nursing the patient prone. This resulted in a most successful 'take' and the method was later extended to all areas where it could be used, with extremely gratifying results, even in the presence of pyocyaneus infection a 50 to 60 per cent. take was recorded.

The American forward surgeons used the 'guillotine' amputation but a study of their methods showed that this was not the 'guillotine' amputation which formed such a distressing feature of German war surgery but was rather the ' cuff' or 'circular flap' amputation done at the lowest possible level, with the object of revising it early. It is still felt, however, that it would be better if all possible skin were saved and no formal amputations done forward but rather an excision only of hopelessly damaged tissue. In the case of some of these so-called 'guillotine' amputations the exposed graft method applied to the raw stump enabled further amputation in the upper limb to be avoided.

Another debatable feature was the insistence on ' defunctioning ' colostomies in large bowel wounds with complete division of the bowel and a skin bridge between; in one case the proximal and distal ends were in opposite flanks! These colostomies almost always demand intraperitoneal closure rather than the simpler and safer extraperitoneal closure which can be employed in the Paul-Mickulicz type of colostomy.

One sphere of war surgery in which the Korean War presented notable advances was in vascular surgery, a number of successful cases of the use of vein autografts to replace severed major arteries were reported and undoubtedly advances of this nature will continue; the role of sympathectomy in arterial injury is still debatable, in one case where this was done in the presence of a ligated popliteal artery the skin of the injured leg survived but, as might be expected physiologically the muscles underwent ischaemic necrosis and there was no sensation in the leg, so a below-knee amputation was performed; it is possible that an above-knee amputation might otherwise have been required, but a study of a large series is necessary to evaluate the merit of the procedure.

A noticeable feature at the base hospital was the 응 excellence of the forward documentation, the notes. of the cases were clear, concise and informative and materially assisted in the handling at base hospitals. One gem, not to be taken as an example, read as follows: 'Ischio-rectal abscess, acute, severe recurrent (I think this guy is nuttier than a fruit cake). Treatment: Wet packs, penicillin. Disposal: To U.K. facilities, Japan. P.S.-Be sure you look at all his tattoos, Jeepers Crow, what a knucklehead.'

Plaster of paris technique was, on the whole, poor, the plaster bandages used lacked the strength of the 'Gypsona' bandages used in British medical units and plasters were often unduly thick, in consequence. 'Plastergrams' (drawing of the wound on the plaster, with added notes and dates) were conspicuous by their absence and the thick plasters, although split, often tended to compress the limb and it was felt that it would be safer completely to bivalve them and maintain them in position with bandages. The 'Tobruk' splint was not used, all fractured femora being evacuated in Spicas.

Three appliances seen at the American Army Hospital in Tokyo shortly after my arrival in 0 Japan are invaluable in war surgery. They were (a) the electric cast cutter, now made in England; since the majority of limb wounds arrive in plaster the swift and painless removal materially assists handling these cases by permitting removal of the 
plaster before anaesthetic; (b) the Stryker bed frame for nursing paraplegics; (c) the electric dermatcme for cutting splitskin grafts rapidly from any part of the body.

Two of these I maraged to acquire, the first by courtesy of the Atom Bomb Casualty Commission who made a surplus cast cutter available, and the second by courtesy of the Royal Australian Electrical and Mechanical Engineers, who made turning frames for me out of steel tubing. The electric dermatome, at $\$ 264$, was beyond my reach!

In short, the surgery of the Korean War, after a shal y start, rapidly settled down to the methods in practice at the end of the last war, with advances notably in vascular surgery and in early skin grc ftirg. The routine administration of antibiotics and reclly adc quate forward transfusion fully justified expectations, and the excellence of air evacuation over all other methods was convincingly demcnstrated.

Death from starvation, or toxaemia as it was euphem sticrlly called in the past, has been eliminated partly by the prevention of infection which leads to protein deficiency and also by ensuring that severely wounded men do not suffer from nits ogen depletion by attention to diet and, if necessary, nasal drip feeding with milk fortified by prcteins such as casilan. Haemoglobin levels and 8 rum protein percentages should be measured at rigular intervals in all seriously ill cases and fresh blood given as required.

Burns, fortunately, did not form a conspicuous feature of the Commonwealth casualties, and Chinese 'Napalm' casualties were treated at P.o.W. hospitals in Korea. Most of the burns we saw were accidentally inflicted, principally in petrol fires.

The forward treatment was by transfusion with whole blood (because of the risk of homologous serum jaundice the Americans were not using plasma or serum in forward areas), penicillin and pressure dressings. On arrival in Japan the exposure methods of Wallace were employed, slightly modific $d$ in that the penicillin was given parenterally as this gives an adequate bacteriostatic concentration in the exuded serum (2.1 units per g.) and is simpler for routine use than the local application of penicillin lactose powder. This method was instituted sometimes as late as six days after burning, but the results were very gratifying and grafting in deep burns was carried out Io to 14 days after exposure. Some gravely infected burns were treated with the Bunyan bag or St: llard envelope, which is still a most satisfactory appliance in a busy general hospital; the comfort of the patient and the ease of nursing are both much appreciated.
Finally, a description of the arrival of a typical convoy in the general hospital may give a picture of the nature of war surgery.

Convoys arrived by air at Iwakuni, an airfield about two hours' journey away by train or launch. Occasionally a casualty who had deteriorated unexpectedly in flight was held at the R.A.A.F. Station hospital, but nearly all cases were entrained or shipped direct to the Commonwealth Hospital. All surgical cases were seen on arrival by the duty surgeon and their condition assessed without disturbing their wounds. Any cases who were in pain, pyrexial or with rapid pulses were admitted to the duty surgeon's ward, the others were distributed to the other surgeons' wards where, after being more thoroughly examined by the medical officer in charge, they were bedded down, fed and given a night's rest, going to the theatre the next day for inspection of wounds and D.P.S. The cases giving rise to concern were taken to the theatre in the evening of their admission and wound inspection carried out, a re-excision often being necessary. Next day, while the duty surgeon recovered from his night's work, the remaining cases were dealt with, often as many as 30 plasters and D.P.S. being performed in the two theatres at one session. Once weekly a complete round of the surgical division took place at which difficult cases were discussed and criticized. There is no doubt that this 'professorial' round, as a Naval visitor christened it, contributed materially to a general improvement of the handling of our cases and enabled us all to benefit from the lessons learned. In any future war it is considered that forward surgeons should 'graduate' via base hospitals so that they may learn by experience which methods used forward give the best results.

\section{Summary}

The tactical medical picture in Korea is briefly described. Present-day methods of treating battle casualties are summarized. The results of these methods applied to the Korean War are given, the mortality rate of 0.35 per cent. being, it is believed, the lowest yet recorded. A description of the work of the Commonwealth General Hospital is given.

\section{Acknowledgments}

I should like first of all to acknowledge my indebtedness to the surgeons, Australian, British and Canadian, whose spirit of co-operation and friendly rivalry made such a success of the Commonwealth hospital; also to the many surgical colleagues of the last war whose ideas I have freely plagiarized. 